\title{
A case study on the influence of mechanical properties on the collapse load of stone arch bridges
}

\author{
J. Díaz, L. Romera \& S. Hernández \\ Structural Mechanics Group, School of Civil Engineering, \\ University of La Coruña, Spain
}

\begin{abstract}
In this paper, the determination of the collapse load of an historical stone arch bridge situated in the Northwest of Spain is accomplished. The arch presents damage and its load bearing capacity is reduced, so repair works and restoration are needed. In such circumstances, the assessment of the ultimate load that the bridge can support is very important and so the limit analysis method is applied, which delivers the collapse load and the failure mechanism considering the hypothesis of plastic collapse of the structure. On the other hand, and taking into account that one of the major drawbacks in the analysis of this type of bridge is the lack of accurate data about material properties, a parametric study is performed selecting from all the mechanical parameters governing the bridge response, those with a wider range of variation or those having a more difficult characterization: masonry and backfill unit weight, compressive strength of the masonry, coefficient of radial friction between voussoirs, height of backing, earth pressure coefficient and load dispersion model. For each one of the properties considered, five values are selected, based upon recommendations found in technical literature or in previous experiences with similar bridges, and a series of analyses are performed, obtaining the influence line of kinematic safety factor, with respect to live load, and the critical failure load variation, with respect to each one of the material properties. Results show that the most significant properties having influence in the collapse load are the compressive strength of the masonry, the earth pressure coefficient and the unit weights of materials.
\end{abstract}

Keywords: stone arch bridge, limit analysis, collapse load. 


\section{Introduction}

The determination of the ultimate load that a bridge can support is always one of the main concerns related with the analysis, maintenance, repair or restoration of this type of infrastructure. This statement, in relation with historical bridges, which are a fundamental value of our cultural heritage, is crucial because, in many of them, aging has caused devastating effects and a rehabilitation must be accomplished as soon as possible. In such circumstances, it is necessary to know the collapse load of the structure, or at least an estimation of it, so repair works can be specified to the right extension. The drawback of the previous requirement is that results must be obtained, often in a short period of time, for a structure of which very few data are known and it becomes complicated and expensive to evaluate with accuracy all the variables that characterize the structural behaviour of the bridge, such as material properties, load history, constructive sequence or geometrical definition, and very often most data is scarce or missing [1].

On the other hand, the special configuration of historical bridges, which are usually supported by masonry arches, demands a specific treatment, being unrealistic to consider the structure totally homogenous, as happens in other typologies or materials. In this paper, in order to deal with these disadvantages, the goal is the development of a procedure to establish, with reasonable reliability, the ultimate load that a bridge can support, taking into account all the special features of masonry structures and maintaining computational cost below certain limits. In that sense, the limit analysis method, considering the hypothesis of plastic collapse of the bridge, has been selected because it is particularly intended for the obtention of failure loads and critical collapse mechanisms of this type of structures and is renowned for giving accurate results, maintaining an affordable computational cost.

However, as has been mentioned previously, one of the major problems of any analysis method applied to historical bridges is the lack of accurate data about many of the features of the structure, and in particular, about the material properties. In order to address this situation, a parametric study is proposed, where a number of mechanical parameters governing the bridge response are selected, according to criteria about the range of variation, for parameters oscillating in a wide spectrum of values, and also about the difficulties in measurement, for those requiring an intervention on the construction. According to that, eight parameters have been selected: masonry and backfill unit weight, compressive strength of the masonry, the coefficient of radial friction between voussoirs, the height of backing, the earth pressure coefficient and the load dispersion model, where the alternatives of uniform dispersion and Boussinesq dispersion are chosen. For each one of the properties considered, five values were selected to try to cover all the range of variation, based on recommendations found in technical literature [2-5] or in previous experiences with similar bridges [6]. Taking all the parameters, a batch of analyses are performed and the influence line of kinematic safety factor, with respect to a concentrated load moving over the deck and the critical failure load variation, with respect to each one of material properties, are obtained. With 


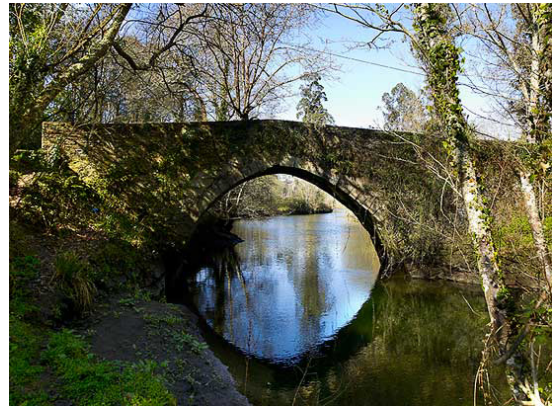

(a) Upstream elevation of the bridge

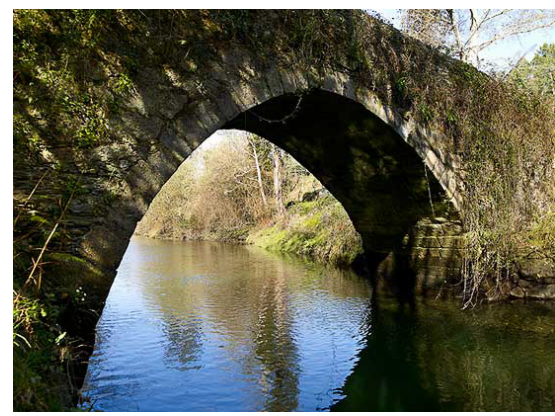

(c) Detail of the arch

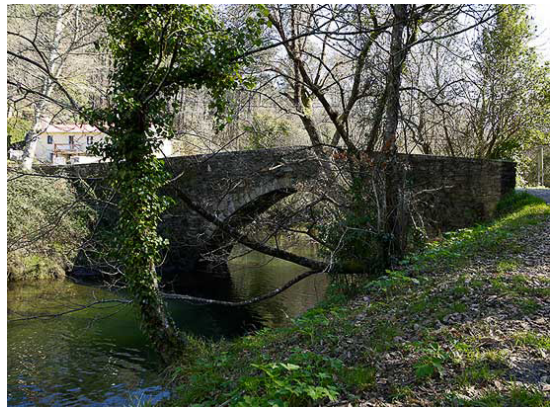

(b) Downstream elevation of the bridge

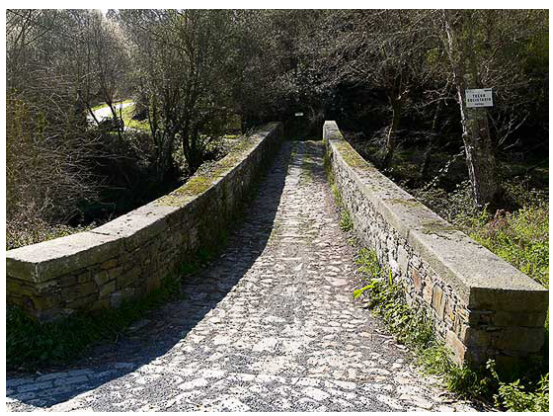

(d) Deck and parapets

Figure 1: Pictures of the Lambre bridge.

these responses, the security of the bridge can be evaluated and at the same time, considerations about the importance of data dispersion in the results can be made, giving a better description of the security level.

The chosen example to illustrate the methodology is a stone arch bridge over the Lambre river (Fig. 1), located in the Northwest of Spain. The results and conclusions from the analyses performed are presented next, starting with a description of the bridge and its characteristics.

\section{Description of the bridge}

The bridge over Lambre river (Fig. 1) is located in the Northwest of Spain, in the region of Galicia and belongs to the municipality of Paderne. It is a gothic bridge from XIV century situated on the ancient road between the cities of Ferrol and Betanzos and it was the obligatory pass for the pilgrims in the English path of the Route to Santiago de Compostela [7]. Because of an ancient local legend related with the feudal lord of the county, the bridge received the nickname of "Ponte do porco" (Wild boar bridge). Nowadays, this name is given to the contemporary 


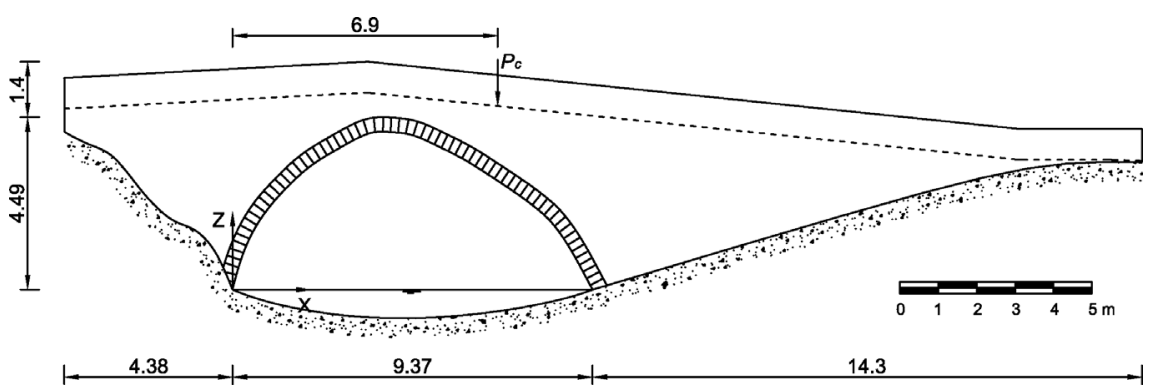

(a) Upstream elevation

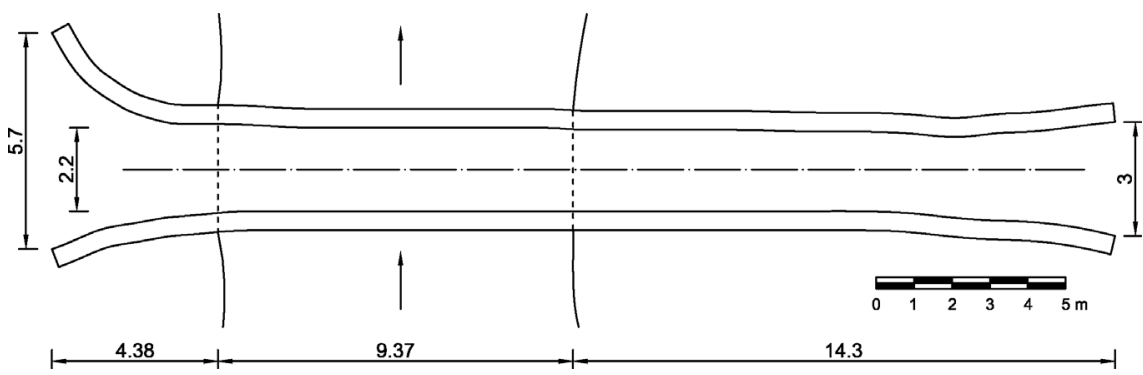

(b) Plan

Figure 2: Dimensions of the Lambre bridge.

bridge situated on the mouth of Betanzos ria, a few kilometres away from the presented here, which now is known as "Ponte Lambre" (Lambre bridge).

The bridge has a single ogival arch, slightly pointed, with a span length of $9.37 \mathrm{~m}$ and a rise value of $4.49 \mathrm{~m}$ (Fig. 2). The width of the vault is $3.2 \mathrm{~m}$ and the minimum width between parapets is $2.2 \mathrm{~m}$ (Fig. 2b). The arch is made of dry masonry with square blocks of granite, a massive igneus rock very common in the region. The blocks have a constant thickness of $380 \mathrm{~mm}$ and the arch rests on the abutments, located underwater. The spandrels are made of schist, a metamorphic rock of lower quality than granite, and also very common in the zone. The backfill is supposed to be a compact material with an angle of friction of $30^{\circ}$ and the coefficient of friction between backfill and masonry has a value of 0.6. On the other hand, the arch presents damage in the right haunch, viewing from upstream side (Fig. 1a), due to a failure in the abutments and, for that reason, the only traffics allowed over the bridge are pedestrians and farm vehicles of the neighbourhood.

With regards to the dead loads considered in the analysis, these are the selfweight of the blocks and the backfill load, defining the unit weight of both materials as a parametric value and also controlling the earth pressure coefficient to evaluate the effect of the horizontal component of backfill pressure and the height of the backing over the arch. The live load was modelled as a concentrated load of $1 \mathrm{kN}$, moving over the deck, whose effect spreads according to an uniform pattern or a Boussinesq model into the fill, with a variable limiting angle. It is on the safe 
Table 1: Mechanical properties of masonry and backfill.

\begin{tabular}{lccccccc}
\hline Material property & Symbol & Units & \multicolumn{5}{c}{ Selected values } \\
\hline Masonry unit weight & $\gamma_{m}$ & $\mathrm{kN} / \mathrm{m}^{3}$ & 18 & 20 & $\mathbf{2 2}$ & 24 & 26 \\
Compressive strength & $\sigma_{c}$ & $\mathrm{MPa}$ & 15 & 20 & 25 & 30 & $\boldsymbol{\infty}$ \\
Coefficient of radial friction & $\mu_{r}$ & - & 0.30 & 0.35 & 0.40 & 0.50 & $\mathbf{0 . 6 0}$ \\
Backfill unit weight & $\gamma_{b}$ & $\mathrm{kN} / \mathrm{m}^{3}$ & 14 & 16 & 18 & $\mathbf{2 0}$ & 22 \\
Height of backing & $h$ & $\mathrm{~mm}$ & $\mathbf{0}$ & 150 & 300 & 450 & 600 \\
Earth pressure coefficient & $k_{0}$ & - & $\mathbf{0 . 0}$ & 0.4 & 0.5 & 0.6 & 0.7 \\
Limiting angle (Uniform) & $\theta_{u}$ & $\circ$ & 24 & 27 & 30 & 33 & 36 \\
Limiting angle (Boussinesq) & $\theta_{b}$ & $\circ$ & 24 & 27 & $\mathbf{3 0}$ & 33 & 36 \\
\hline
\end{tabular}

side to consider this type of load, as a normal vehicle has its weight divided into several axis. A comparison of this point load with an equivalent distributed load in the length of a conventional vehicle shows an increment in the load capacity of $35.4 \%$. On the other hand, and since the only traffic allowed over the bridge are pedestrians and farm vehicles, it is not necessary to take into account dynamic effects.

Because of the already mentioned scattering in material data, a parametric study is conducted selecting the eight properties shown in Table 1, where five values for each one of them are considered in the analysis. The numbers highlighted in bold typeface are the nominal values taken by the parameters when remain constant. On the contrary, some properties have been discarded from the parametric study because do not have a decisive influence over the collapse load, based on results obtained in preliminary analyses.

\section{Limit analysis}

The limit analysis method has demonstrated to be a powerful and reliable tool and has been applied to numerous situations in order to assess the failure load and the critical collapse mechanism of stone arch bridges. See, for instance, the works by Drosopoulos et al. [8] or those by Cavicchi and Gambarotta [9]. The application of two-dimensional limit analysis to establish the load bearing capacity of a masonry arch bridge is based on the following hypothesis, according to Heyman [10], some of which are slightly modified in this study:

- Masonry has not tensile strength. This is true in this case for the joints between voussoirs, and it is on the safe side for the stone, as it presents certain tensile strength.

- Sliding failure mode cannot occur, which means that friction between blocks is high enough so that they will not collapse sliding one on another. This is 


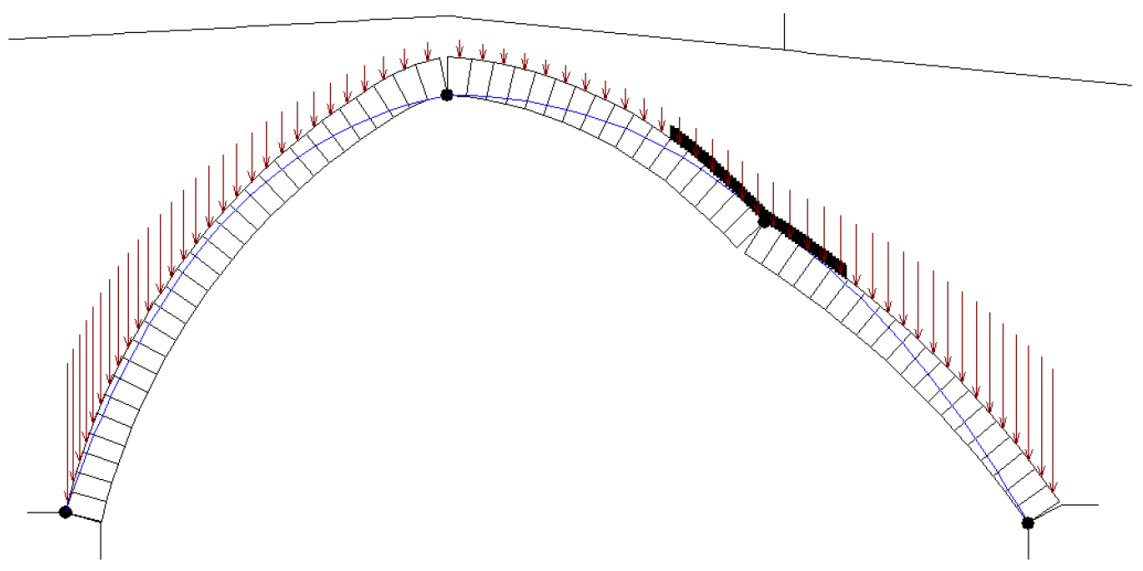

Figure 3: Critical collapse mechanism and thrust line with four hinges.

true in most of the cases for this bridge, but when the coefficient of friction in radial direction between voussoirs is selected as a variation factor, some values lead to sliding collapse modes.

- Stone has an infinite compressive strength, which is equivalent to consider that compressive stresses are low compared with the stone failure stress, and so crunching of the material is not possible. As this assumption is on the unsafe side, the compressive strength of the stone has been selected as a variation parameter, with four different finite values. Infinite compressive strength has also been selected as the fifth value of the parameter, as Heyman proposes.

Considering the previous hypothesis and the limit analysis upper-bound theorem, four hinges are needed in the case of this bridge to develop a kinematic admissible collapse mechanism. These hinges are formed when the thrust line is tangent to the arch parament (Fig. 3) and the kinematic safety factor [11] is the load multiplier $P$ applied to live load which causes collapse. The lowest kinematic safety factor is designated as the critical load multiplier $P_{c}$. As the selected value for the live load is $1 \mathrm{kN}$, those multipliers are directly the failure load and the critical failure load, respectively.

The advantage of this method is that provides collapse load estimations and the associated failure mechanisms with low computational cost. However, some disadvantages arise, like the impossibility of describe intermediate states of the structure before the collapse, or the validity of the hypothesis previously made. The first one can only be addressed with other analysis methods, like, for instance, the finite element method, but the second inconvenience can be avoided defining several modelling situations, like in the parametric study here presented. This study has been carried out using the code RING 1.5, by Matthew Gilbert [12]. 


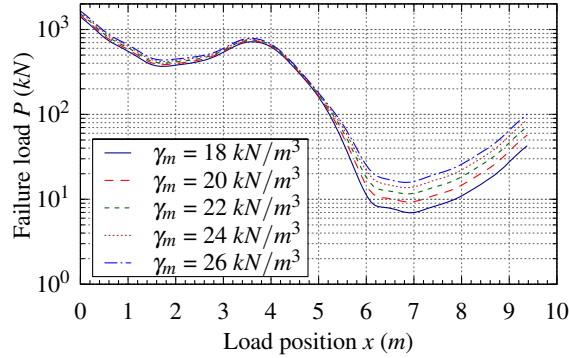

(a) Masonry unit weight $\gamma_{m}$

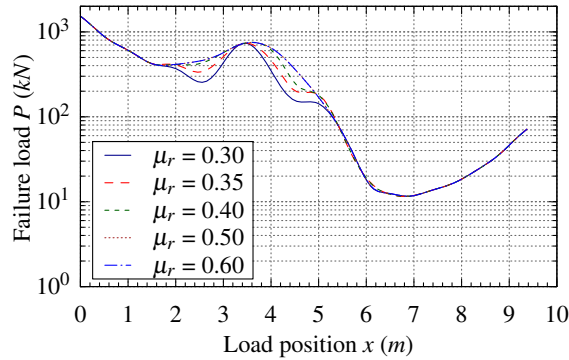

(c) Coefficient of radial friction $\mu_{r}$

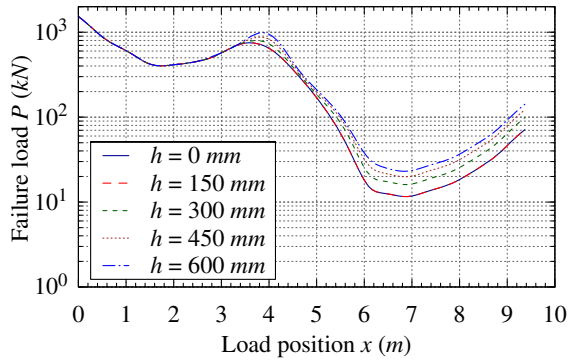

(e) Height of backing $h$

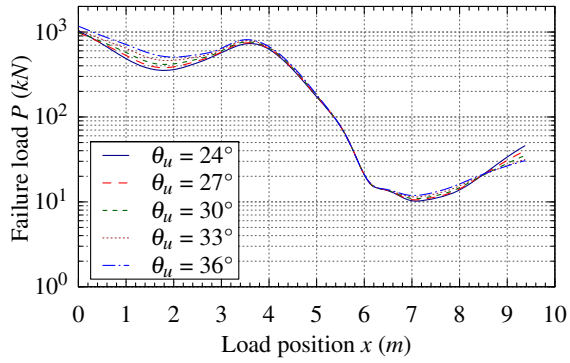

(g) Limiting angle $\theta_{u}$

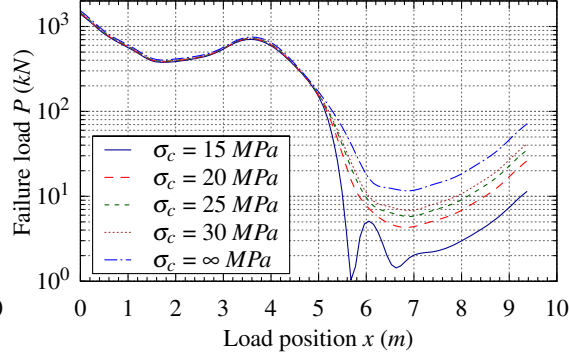

(b) Compressive strength $\sigma_{c}$

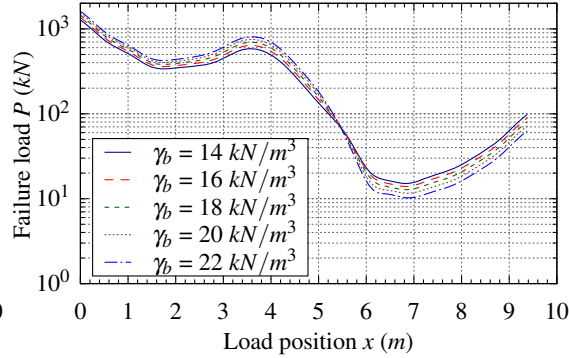

(d) Backfill unit weight $\gamma_{b}$

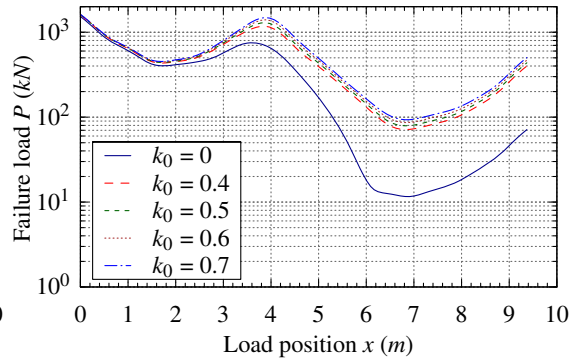

(f) Earth pressure coefficient $k_{0}$

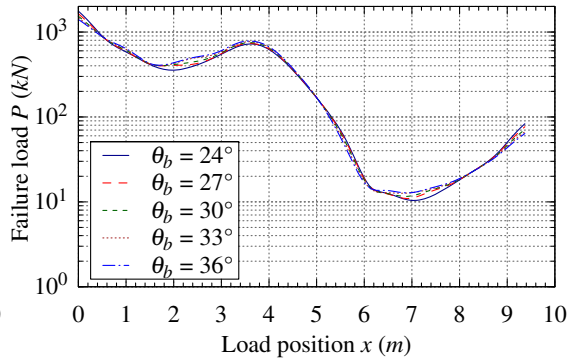

(h) Limiting angle $\theta_{b}$

Figure 4: Influence lines of kinematic safety factor with respect to live load. 


\section{Results and discussion}

The applied methodology returns two types of results: the influence line of kinematic safety factor with respect to live load (Fig. 4), where a logarithmic scale has been used on the axis of ordinates to highlight the results in the range of interest, and the critical failure load variation, with respect to each material property (Fig. 5). The first value gives the collapse load for each position over the bridge of the live load and the second shows the effect on the critical failure load of all the range of values of each factor considered in the parametric study. Results also show that the critical failure load $P_{c}$ is situated at 6.9 metres from the origin (Fig. 2a), being its value dependant on the parameters. Next, some interpretations are done about the effect on the results of each factor from the parametric study.

Masonry unit weight has no influence over failure load when this is placed in the left half of the bridge (Fig. 4a), but its effect is noticeable when the load acts over the damaged zone. The critical failure load is sensitive to this parameter (Fig. 5a), being its contribution directly proportional, with variations about $220 \%$.

The contribution of compressive strength to failure load is significant (Fig. 4b), specially when the value is low enough to activate the compressive failure mode. In the same way, the effect of this parameter on critical failure load becomes more important in the lower part of the range (Fig. 5b), when the stone failure is possible.

The coefficient of radial friction has little influence in the results (Fig. 4c), only on the left part of the arch, when the value of the coefficient is low enough to produce sliding collapse mode. For the same reason, $P_{c}$ is insensitive to this parameter (Fig. 5c).

The effect of backfill unit weight is noticeable in all the positions of live load (Fig. 4d) and it is worth mentioning that this is the only parameter whose effect is inversely proportional over critical failure load (Fig. 5d).

Regarding to the height of backing, it has a behaviour quite similar to masonry unit weight (Fig. 4e), and the same happens with critical failure load (Fig. 5e), although the effect is more pronounced with higher values of the parameter.

The earth pressure coefficient has a significant impact on the kinematic safety factor (Fig. 4f) and is remarkable its increment when the horizontal component of backfill load is considered. Consequently, $P_{c}$ is very sensitive to this parameter (Fig. 5f) which increases the load bearing capacity up to four times.

Finally, with respect to limiting angle, its variation is not significant, both for uniform dispersion (Fig. 4g) and for Boussinesq model (Fig. 4h) in any position of live load. On the other hand, $P_{c}$ oscillates in a margin of about $10 \%$ (Figs. $5 \mathrm{~g}$ and $5 \mathrm{~h})$.

\section{Conclusions}

In this work, the limit analysis method has been applied to the obtention of collapse load of an historical stone arch bridge, taking into account the variation on mechanical properties of masonry and backfill. Finally, the following conclusions can be drawn: 


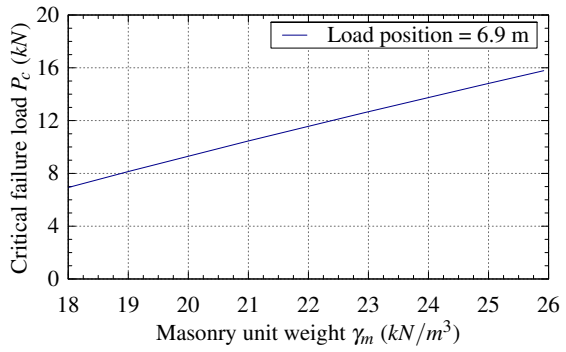

(a) Masonry unit weight $\gamma_{m}$

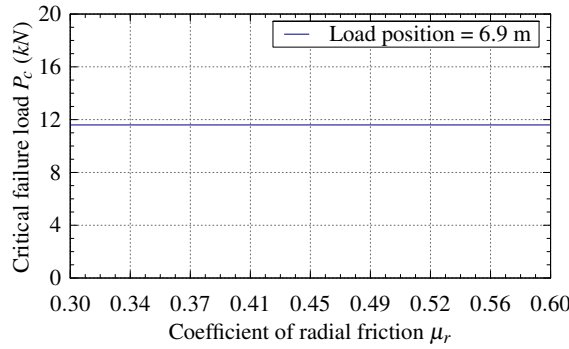

(c) Coefficient of radial friction $\mu_{r}$

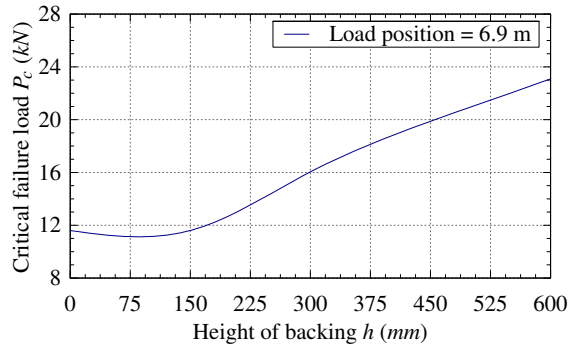

(e) Height of backing $h$

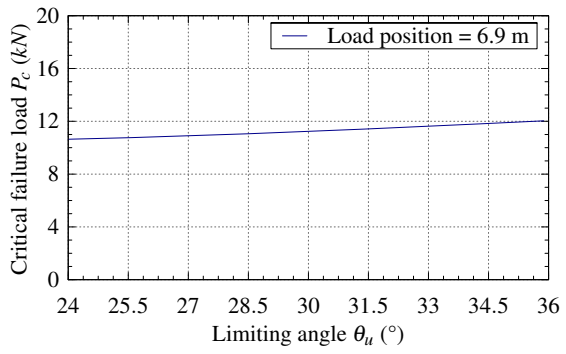

(g) Limiting angle $\theta_{u}$

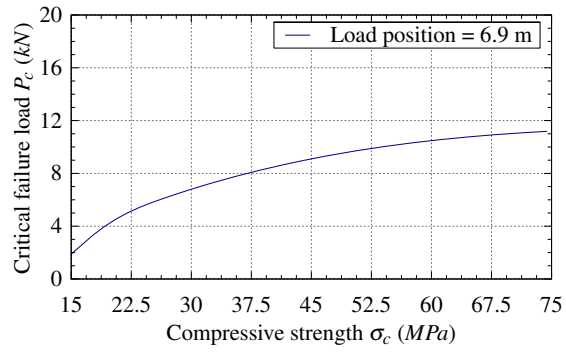

(b) Compressive strength $\sigma_{c}$

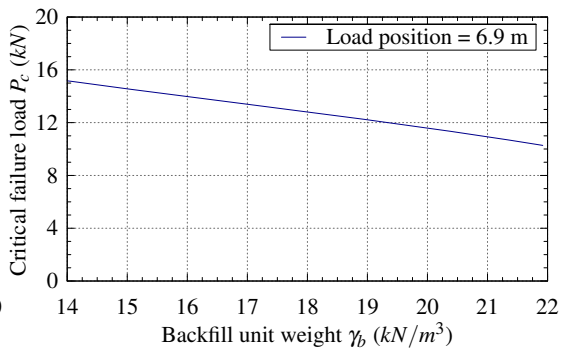

(d) Backfill unit weight $\gamma_{b}$

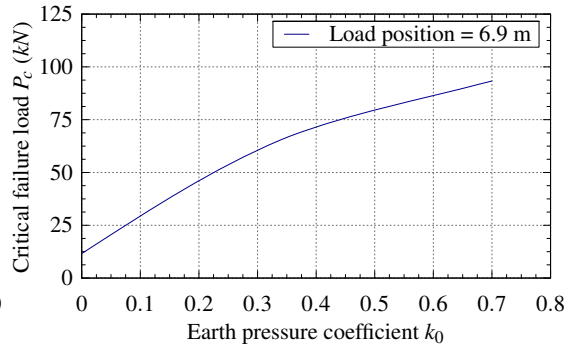

(f) Earth pressure coefficient $k_{0}$

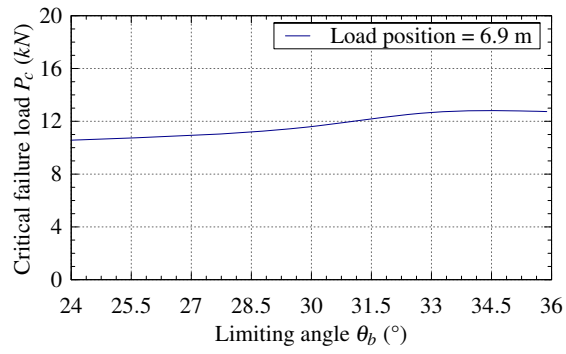

(h) Limiting angle $\theta_{b}$

Figure 5: Critical failure load variation with respect to material properties. 
1. Special attention must be paid to the evaluation of geometrical and mechanical data of the structure, as they have a decisive importance on the accuracy of the response and very often its obtention is difficult and costly, because of the special features of this type of constructions. The methodology here presented allows, in a simple and affordable way, the estimation of relevant information about the condition of masonry bridges, taking into account the lack of accurate data about mechanical properties.

2. The limit analysis method is an efficient and inexpensive tool to assess the security level of masonry arch bridges, providing also the collapse mechanism and allowing the precise determination of critical zones of the structure.

3. The most influential properties over the collapse load, in the case of this bridge, have been the masonry and backfill unit weight, the compressive strength and the earth pressure coefficient, and so their values must be carefully selected, being advisable in some cases carrying out tests to check the nominal values found in literature.

4. The critical collapse load has proved to be not very sensitive to the coefficient of radial friction and to the load dispersion model, and so nominal values of these parameters can be selected without further considerations.

\section{References}

[1] Lourenço, P.B., Guidelines for the analysis of historical masonry structures. Finite Elements in Civil Engineering Applications. Proceedings of the Third DIANA World Conference, eds. M.A. Hendriks \& J.G. Rots, Swets \& Zeitlinger: Lisse, pp. 241 - 248, 2002.

[2] Carmichael, R.S., Handbook of Physical Properties of Rocks, volume II. CRC Press: Boca Raton, Florida, 2000.

[3] Fanning, P. \& Boothby, T., Three-dimensional modelling and full-scale testing of stone arch bridges. Computers \& Structures, 79(29), pp. $2645-$ 62, 2001.

[4] Brencich, A. \& Sabia, D., Experimental identification of a multi-span masonry bridge: the tanaro bridge. Construction and Building Materials, 22(10), pp. 2087 - 99, 2008.

[5] Vasconcelos, G., Lourenço, P., Alves, C. \& Pamplona, J., Ultrasonic evaluation of the physical and mechanical properties of granites. Ultrasonics, $48(5)$, pp. $453-466,2008$.

[6] Díaz, J., Romera, L. \& Hernández, S., Non-linear finite element analysis and limit analysis comparison of the caaveiro stone arch bridge. Proceedings of the Tenth International Conference on Structural Repairs and Maintenance of Heritage Architecture, ed. C. Brebbia, Wessex Institute of Technology: Ashurst Lodge, Southampton, pp. 555 - 566, 2007.

[7] Alvarado, S., Durán, M. \& Nárdiz, C., Pontes históricas de Galicia. Xunta de Galicia y Colegio de Ingenieros de Caminos, Canales y Puertos: Santiago de Compostela, 1989. (In Galician). 
[8] Drosopoulos, G.A., Stavroulakis, G.E. \& Massalas, C.V., Limit analysis of a single span masonry bridge with unilateral frictional contact interfaces. Engineering Structures, 28(13), pp. 1864-1873, 2006.

[9] Cavicchi, A. \& Gambarotta, L., Lower bound limit analysis of masonry bridges including arch-fill interaction. Engineering Structures, 29(11), pp. 3002-3014, 2007.

[10] Heyman, J., The Masonry Arch. Ellis Horwood: Chichester, 1982.

[11] Heyman, J., The Stone Skeleton: Structural Engineering of Masonry Architecture. Cambridge University Press: Cambridge, 1995.

[12] Gilbert, M., RING. Program Reference Guide. The University of Sheffield: Sheffield, 2005. 